\title{
Results of coronary artery bypass grafting in patients with chronic obstructive lung disease
}

\begin{abstract}
This work is relevant because it studies the effect of chronic obstructive pulmonary disease on the incidence of complications after coronary artery bypass grafting in patients with ischemic lung disease. 118 histories of patients, who underwent CABG under conditions of artificial circulation and without it, on a working heart, were analyzed. It was found that in patients with CABG under conditions of infarction and concomitant chronic obstructive pulmonary disease, the period of artificial ventilation was significantly longer among all the assessed complications and features of the postoperative period than in the group of patients with CABG performed on a working heart.
\end{abstract}

Volume 6 Issue I - 2019

\author{
Shlyk IF, Sidorov RV, Shchetko VN, Sizyakina \\ LP, Shlyk SV \\ Rostov State Medical University, Russian Federation
}

Correspondence: Shlyk IF, Rostov State Medical University,

Russian Federation, Email sushkunaif@mail.ru

Received: November 28, 2017 | Published: February 28, 2019

Keywords: Coronary artery bypass grafting, chronic obstructive pulmonary disease

Abbreviations: IHD, chemic heart disease; MI, myocardial infarction; $\mathrm{ACF}$, acute cardiovascular failure; $\mathrm{AC}$, artificial circulation; CABG, coronary artery bypass graft; COPD, chronic obstructive pulmonary disease; DM, diabetes mellitus; $\mathrm{CKD}$, chronic kidney disease; ONPUMP, coronary artery bypass graftin conditions of artificial circulation; OFFPUMP, coronary artery bypass graft without an artificial circulation device

\section{Introduction}

In recent years, there are numerous data confirming the epidemiological and pathogenetic relationship of coronary heart disease and chronic obstructive pulmonary disease (COPD). ${ }^{1-5} \mathrm{~A}$ number of studies have demonstrated the mutual aggravating effect of these diseases. ${ }^{6-9}$ Among the methods of surgical treatment of ischemic heart disease, coronary artery bypass grafting (CABG) is the leading place, along with percutaneous interventions on the coronary arteries. ${ }^{10,11}$ The immediate and long-term results of $\mathrm{CABG}$, on the one hand, are determined by the surgical features of the performed intervention. ${ }^{12-15}$ The frequency and nature of perioperative complications can vary significantly depending on the use of autoarterial or autovenous shunts, the operation with the use of artificial circulation ot without it. A significant contribution to the formation of the risk of perioperative complications is made by the nature and severity of the concomitant diseases affecting the immediate results of $\mathrm{CABG}^{8,16}$ Among them, the most studied are diabetes mellitus (DM) and chronic kidney disease (CKD). To a much lesser degree, the effect of COPD on the nature and frequency of perioperative complications has been studied. In connection with this, it is of interest to study the risk of both cardiovascular and extracardiac complications in the peri- and postoperative period in patients with COPD who underwent CABG surgery.

\section{Target}

To study the effect of COPD on the results of surgical treatment of cardiac ischemia (CI), depending on the method of surgical treatment.

\section{Materials and methods}

A retrospective analysis of the results of surgical treatment of 118 patients with CI with concomitant COPD was performed in the cardiosurgical department of the Rostov State Medical University clinic between 2009 and 2016:60 patients operated under conditions of artificial circulation (AC), 58 patients underwent surgery working heart without AC using OPCAB technology (Table 1).

\begin{tabular}{llll}
\multicolumn{2}{l}{ Table I Intraoperative indicators } & & \\
\hline Indicators & $\begin{array}{l}\text { ONPUMP } \\
\mathbf{n}-60\end{array}$ & $\begin{array}{l}\text { OFFPUMP } \\
\mathbf{n}-58\end{array}$ & $\mathbf{P}$ \\
\hline $\begin{array}{l}\text { Operation time, min. } \\
\text { Index of revascularization, }\end{array}$ & $268,7 \pm 53,6$ & $219,6 \pm 46,3$ & 0,00009 \\
M $\pm m$ & $3,2 \pm 0,7$ & $3,5 \pm 0,9$ & 0,045 \\
Blood loss, $\mathrm{ml}$ & $875,4 \pm 198,7$ & $859,8 \pm 21 \mathrm{I}, \mathrm{I}$ & 0,68 \\
\hline
\end{tabular}

\section{Results and discussion}

The spontaneous when comparing the groups of patients with CABG without IR and CABG with IR at a similar volume of revascularization, a shorter time of operative intervention in the first group was established. The volume of intraoperative blood loss did not depend on the method of CABG. The average volume of blood loss by drainages and the need for replacement blood transfusion did not differ significantly after operations in $\mathrm{AC}$ and without it. The duration of the ventilator after the operation was significantly shorter after CABG without AC. The average residence time of patients in the cardiac recovery department was also less after operations without AC. However, the time of patients' stay in the hospital as a whole in groups ONPUMP and OFFPUMP did not differ significantly. Myocardial infarction (MI) in both groups was not. The incidence of acute heart failure (AHF) after surgery with and without AC was not significantly different. Respiratory failure with impaired oxygenating function of the lungs and the need for prolonged artificial ventilation of the lungs developed much more often in patients operated under AC conditions.

Reinternotomy for bleeding was performed only by 1 patient operated with AC. There was no significant difference in the incidence of pulmonary complications, and if pneumonia was diagnosed only in 1 patient of the ONPUMP group, postoperative pleurisy developed much more often. In 1 patient, operated with $\mathrm{AC}$, against the background of AHF, multi-organ failure developed, requiring longterm intensive therapy, including a multi-day ultra-filtration session. Among the relatively small number of cerebrovascular complications, only diffuse encephalopathy was noted, whose clinical manifestations were observed, respectively, in $5.0 \%$ and $1.7 \%$ of patients in the ONPUMP and OFFPUMP groups $(\mathrm{p}>0.05)$. In the incidence of 
infectious complications, there were no significant differences: inflammation of the soft tissues of the sternum appeared, respectively, in $6.6 \%$ and $5.2 \%$ of patients, and mediastinitis - in only 1 patient, operated without AC.

\section{Conclusion}

CABG operations without AC in patients with COPD are accompanied by a lower incidence of acute respiratory failure, shorter duration of ventilation, and a less frequent need for prolonged ventilation, which significantly reduces the time of patients' stay in cardiac recovery.

\section{Acknowledgments}

None.

\section{Conflicts of interest}

The authors state that there is no conflict of interest.

\section{References}

1. Curkendall SM, DeLuise C, Jones JK, et al. Cardiovascular disease in patients with chronic obstructive pulmonary disease, Saskatchewan Canada cardiovascular disease in COPD patients. Ann Epidemiol. 2006;16(1):63-70

2. Lee HM, Lee J, Lee K, et al. Relation between COPD severity and global cardiovascular risk in US adults. Chest. 2012;142(5):1118-1143.

3. Ryan M, Suaya JA, Chapman JD, et al. Incidence and cost of pneumonia in older adults with COPD in the United States. PLoS One. 2013;8(10):e75887.

4. Melikulov AKh, Maglakelidze DA. Possible mechanisms and strategies for preventing atrial fibrillation after open-heart surgery. Annals of Arrhythmology. 2012;1:13-19.

5. Sidorov RV, Martynov DV, Petyaev AM, et al. Prevention of reperfusion injury of the myocardium after the operation of direct myocardial revascularization in conditions of artificial circulation. Cardiology and Cardiovascular Surgery. 2009;2(6):35-37.
6. Huiart L, Ernst P, Suissa S. Cardiovascular morbidity and mortality in COPD. Chest. 2005;128(4):2640-2646.

7. Molinos L, Clemente MG, Miranda B, et al. Community-acquired pneumonia in patients with and without chronic obstructive pulmonary disease. $J$ Infect. 2009;58(6):417-424.

8. Sin DD, Man SF. Chronic obstructive pulmonary disease as a risk factor for cardiovascular morbidity and mortality. Proc Am Thorac Soc. 2005;2(1):8-11.

9. Avdeev SN, Baymakanova GE. COPD and cardiovascular diseases: mechanisms of association. Pulmonology. 2008;1:5-13.

10. Alwaqfi NR, Khader YS, Ibrahim KS, et al. Coronary artery bypass grafting: 30-day operative morbidity analysis in 1046 patients. J Clin Med Res. 2012;4(4):267-273.

11. Buch P, Friberg J, Scharling H, et al. Reduced lung function and risk of atrial fibrillation in the Copenhagen City Heart Study. Eur Respir J. 203;21(6):1012-1016

12. Dublin S, French B, Glazer NL, et al. Risk of new-onset atrial fibrillation in relation to body mass index. Arch Intern Med. 2006;166(21):23222328.

13. Dun W, Boyden PA. Aged atria: electrical remodeling conducive to atrial fibrillation. J Interv Card Electrophysiol. 2009;25(1):9-18.

14. Mareedu RK, Abdalrahman IB, Dharmashankar KC, et al. Atrial flutter versus atrial fibrillation in a general population: differences in comorbidities associated with their respective onset. Clin Med Res. 2010;8(1):1-6.

15. Shlyk IF, Sidorov RV, Eliseev DN, et al. Markers of the pathogenesis of acute coronary syndrome in patients with type 2 diabetes mellitus in predicting a long-term adverse outcome. Bulletin of the National Medical and Surgical Center. 2016;11(4):69-72.

16. Pavlenko VI. Interrelation of clinical and electrocardiographic signs of stenocardia in patients with COPD. Far Eastern Medical Journal. 2008;1:19-21. 